TM-1687

\title{
Degradation Studies of Fermilab Low Beta Quadrupole Cable *
}

\author{
S. A. Gourlay \\ Fermi National Accelerator Laboratory \\ P.O. Box 500 \\ Batavia, Illinois 60510 \\ M. Garber \\ Brookhaven National Laboratory \\ Upton, New York 11973 \\ J. Royet and R. M. Scanlon \\ Lawrence Berkeley Laboratory \\ Berkeley, California 94720
}

October 1990

* Presented at the 1990 Applied Superconductivity Conference, Snowmass, Colorado, September 24-28, 1990. 


\author{
S.A. Gourlay, Fermilab \\ P.O. Box 500 \\ Batavia, Illinois 60510 \\ M. Garber, Brookhaven National Laboratory \\ Upton, New York 11973 \\ J. Royet, R.M. Scanlan, Lawrence Berkeley Laboratory \\ 1 Cyclotron Road \\ Berkeley, California 94720
}

\title{
Abstract
}

The production of high gradient superconducting quadrupoles for the Tevatron D0/B0 Low Beta insertion is currently underway at Fermilab.The two-shell design utilizes a 36-strand Rutherford style cable produced by Lawrence Berkeley Laboratory. A measure of cable quality is usually given by a comparison of the critical current of the cable with the sum of the critical currents of the strand. A recent study involving variations in the cabling conditions and dimensional parameters has resulted in a significant decrease in degradation. Over the period of cable production degradation has been reduced from an average of $12 \%$ to less than $4 \%$. Some cable samples measured by Brookhaven National Laboratory exhibit Jc's in excess of $3100 \mathrm{~A} / \mathrm{mm}^{2} @ 5 T$. The adjustments to the cabling procedure which are believed to be responsible for the reduction in Jc degradation will be discussed.

\section{Introduction}

The Fermilab Tevatron Low Beta system has been designed to provide a high luminosity interaction region at DO and an identical insertion which will be installed as an upgrade to the current Low Beta system at B0 1,2,3,4. The project requires the construction and installation of 20 two-shell high gradient superconducting quadrupoles 5 as well as low current single-shell high gradient trims ${ }^{6}$ and conventional Tevatron correction coils.

\section{Conductor}

The specifications for the Low Beta two-shell quadrupoles set strict performance requirements on the strand (Tab. 1).

Table 1 . Strand Specifications

Diameter (mm)

Filament twist

Copper to NbTi ratio

Number of filaments

Filament spacing (s/d)

Filament diameter

Minimum filament spacing

Ic at $4.2 \mathrm{~K}$ and $6 \mathrm{~T}$

$\mathrm{Jc}$ at $4.2 \mathrm{~K}$ and $5 \mathrm{~T}$

Twelve billets of material, yielding approximately 7 million feet of strand, were produced for the project by IGC/Advanced Superconductor, Inc.. The composite, $\mathrm{Nb} 46.5 \mathrm{wt} \% \mathrm{Ti}$ and $\mathrm{Cu}$, was drawn down to the final diameter through an anneal and coldwork schedule designed to optimize the maximum critical current density $7,8,9$. The results of short sample measurements made at Brookhaven National Laboratory for representative strands from each billet gave an average strand Ic of over 212 amps @ $4.2 \mathrm{~K}$ and $6 \mathrm{~T}$

Manuscript received September 24, 1990.

\section{Cable}

The 36 strand, Rutherford style cable was produced by Lawrence Berkeley Laboratory on the experimental cabling machine. The LBL machine was chosen because of its 36 strand capability and the exacting mechanical tolerances of the cable (Tab. 2).

Table 2. Cable Specifications

Number of Strands

Twist (Lay length)

Mid-thickness

Width

Keystone angle

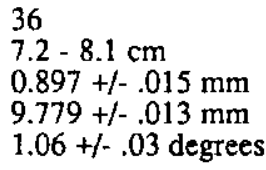

\section{Degradation Studies}

Early cabling attempts resulted in degradations of approximately $10-12 \%$. Degradation on 23-strand and 30-strand SSC cables made on the same equipment typically range from $2-5 \%$. Strand critical currents are not corrected for self field effect; the reported degradations are, therefore, lower (of order $5 \%$ ) than the true degradaton. All cable measurements do, however, take into account the self field effect of the cable which is larger and more variable than that for the surand 10 .

The high gradient quadrupoles require conductor with the highest current density now available and any reduction in the cable critical current would result in diminished operating margin of the magnets. Over the duration of the cabling run, which lasted 24 months, the degradation decreased substantially. The degradation and critical current density are shown chronologically as a function of run in Figs. 1 and 2. Details of the procedures used in measuring the cable critical current can be found in references 11 and 12 .

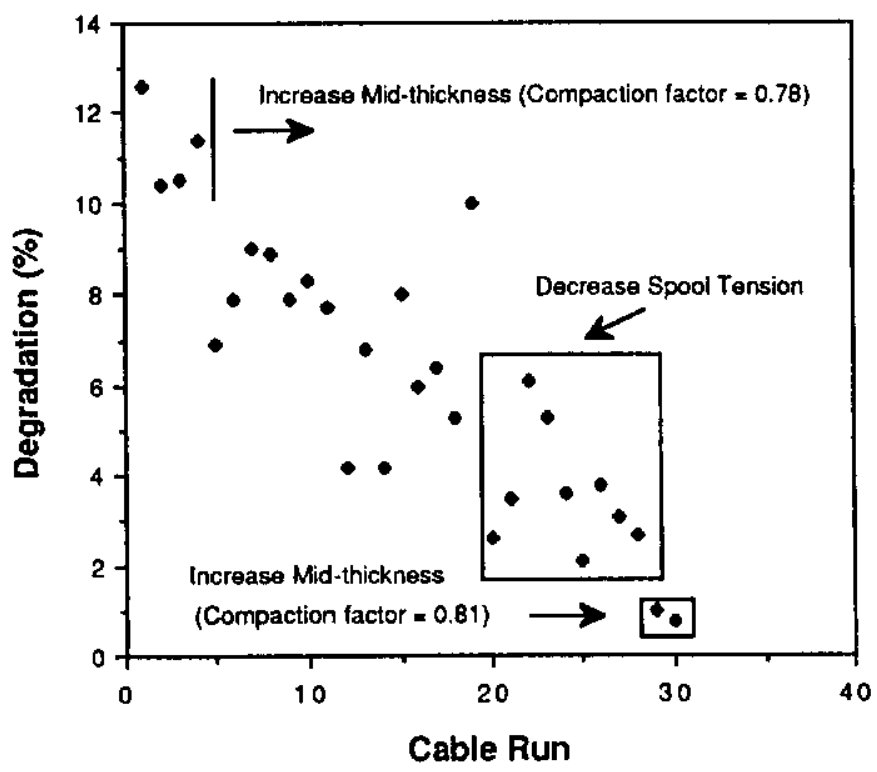

Figure 1. Cable degradation as a function of run illustrating the reduction in degradation as improvements were made. 


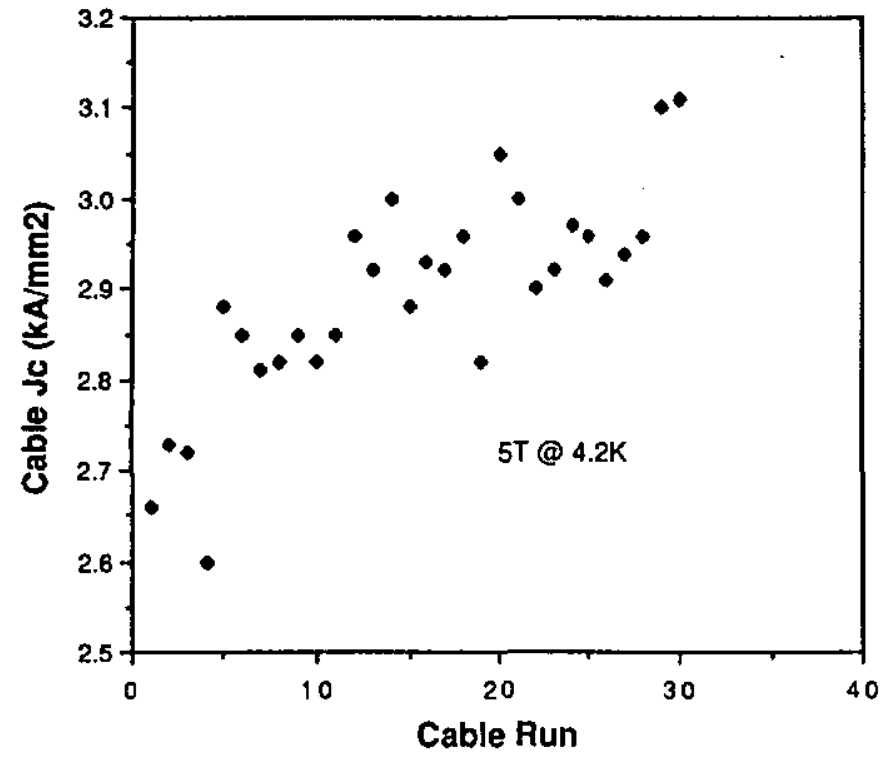

Figure 2. Cable critical current density (Jc in $\mathrm{kA} / \mathrm{mm}^{2} @ 4.2 \mathrm{~K}$ and 5T) as a function of cable run. The two points above $3100 \mathrm{~A} / \mathrm{mm}^{2}$ are for cable with a thin edge compaction factor of 0.81 .

The early improvement in degradation was obtained by a slight increase in the mid-thickness of the cable, thereby reducing the compaction of the thin edge. It is well known that the thin edge compaction plays a strong role in degradation of keystoned cables. The compaction factor, defined as $t / 2 \mathrm{~d}$, where

$$
\begin{aligned}
& t=\text { thickness of thin edge } \\
& d=\text { strand diameter }
\end{aligned}
$$

is 0.76 using the cable parameters given in Tab. 2 . After the first four cable runs, the mid-thickness was increased to $0.909 \mathrm{~mm}$ giving a compaction factor for the thin edge of 0.78 , resulting in a decrease in degradation while remaining within the allowed tolerances.

Additional improvements were probably due to contributions from a variety of sources, such as minor adjustments in operation and setup of the cabling machine and careful attention to the overall stability of the machine during each run. Despite the gradual decrease in degradation, other factors which could possibly contribute to the larger than normal degradations observed were investigated.

It had been observed that there is a correlation between strand diameter and degradation. Figure 3 is a plot of degradation as a function of strand diameter for several cable designs currently in use. The values for the degradation are only approximate. The correlation between diameter and degradation suggests that the specific tension be scaled according to the diameter of the wire. It should be noted that this correlation can only exist in the absence of other contributing factors.

The spool tension used for the first 19 runs was $2.3-2.5 \mathrm{Kg}$. If the tension is scaled from the $0.81 \mathrm{~mm}$ diameter SSC Inner wire (spool tension $=3.2-3.6 \mathrm{Kg}, \mathrm{Cu} /$ superconductor ratio $=1.3$ ) to the 0.528 $\mathrm{mm}$ diameter Low Beta wire ( $\mathrm{Cu} /$ superconductor ratio $=1.5)$ then the ideal spool tension should be less than $1.8 \mathrm{Kg}$. The spool tension was reduced to $1.4-1.6 \mathrm{Kg}$ for the last nine cabling runs, which reduced the degradation to an average of less than $4 \%$.

The extent of the contribution of the thin edge compaction of the Low Beta cable was investigated further by increasing the midthickness (beyond the allowed tolerances) such that the compaction factor was raised to 0.81 . Two short cable runs were made with increased mid-thickness, resulting in degradations of less than $1 \%$ and cable Jc's in excess of $3100 \mathrm{~A} / \mathrm{mm}^{2}$.

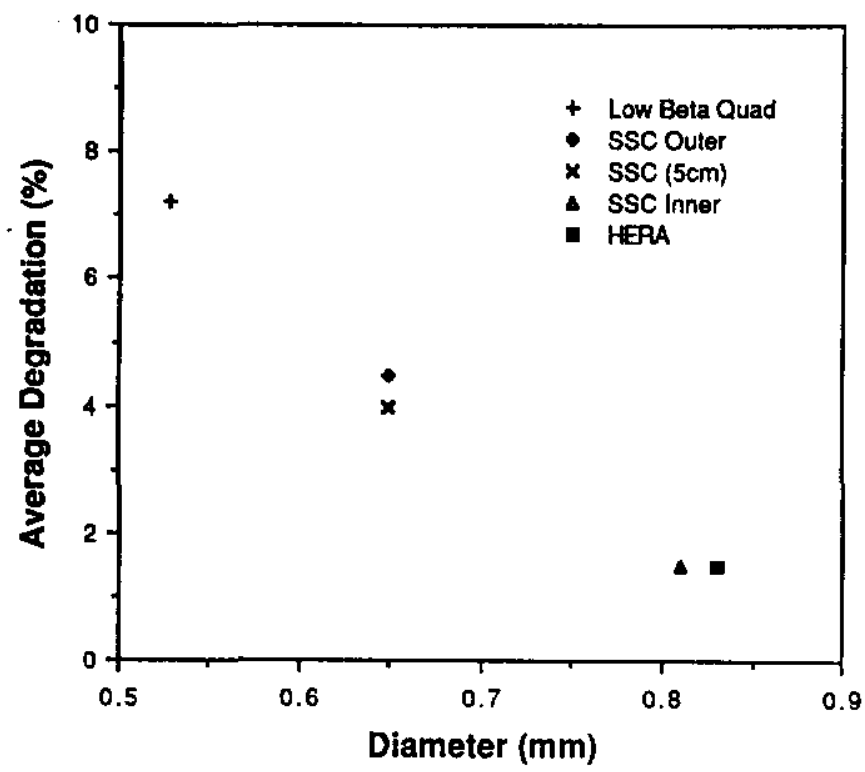

Figure 3. Average cable degradation plotted against strand diameter for a few cable designs currently in use. The empirical relationship between strand diameter and degradation pointed to strand tension as a possible contributor to the degradation of Low Beta Quad cable. The degradation of $7.2 \%$ for the Low Beta cable is taken from samples after the first mid-thickness change was made and prior to a reduction in strand tension.

\section{Conclusions}

The cabling degradation of 36 strand Low Beta cable has been reduced over the production period from a high of over $12 \%$ to less than $1 \%$, resulting in cable with a Jc of over $3100 \mathrm{~A} / \mathrm{mm}^{2}$. This was accomplished primarily through reduced spool tension and a slight increase in mid-thickness. Other, less tangible changes based on running experience, improved the stability of the cabling machine and thereby decreased degradation. General discussions of the parameters affecting cable degradation can be found in references 13 and 14.

\section{Acknowiedgements}

Fermilab wishes to thank Bill Sampson's group at Brookhaven National Laboratory for providing short sample strand and cable measurements and Clyde Taylor's group at Lawrence Berkeley Laboratory for producing the cable for the Low Beta Project. In addition we wish to acknowledge the care and attention to detail by the cabling crew (Bob Jensen, Bob Tuskey, Scott Graham, Roy Hannaford and Hugh Higley) which made these improvements possible.

\section{References}

1. A.D. McInturff et al.,"The Fermilab Collider D0 Low Beta System", European Particle Accelerator Conference, Rome, Italy, 1988.

2. D. Johnson, "The B0 Low Beta Insertion Design for the Tevatron", IEEE Trans. on N.S., NS-32, 1672, (1985).

3. K. Koepke, H.E. Fisk, G. Mulholland, H. Pfeffer, "The Tevatron B0 Low Beta System", IEEE Trans. on N.S., NS-32, 1675, (1985).

4. D. Finley, R. Johnson and F. Willeke, "Control and Initial Operation of the Fermilab Low Beta Insertion", IEEE Trans. on N.S., NS-32, 1678, (1985)

5. A.D. McInturff, "High Field Magnet Proposal", FNAL TM-1425, 1985 
6. P.M. Mantsch et al.,"A New High Gradient Correction Quadrupole for the Fermilab Luminosity Upgrade", Particle and Accelerator Conf., Chicago, Il., 1989 (to be published).

7. D.C. Larbalestier, A.W. West, W.S. Starch, W.Warnes, P.Lee, W.K. McDonald, P.M. O'Larey, K. Hemachalam, B. Zeitlin, R. Scanlan, C. Taylor, IEEE Trans. Mag- 2I, p.269 (1985).

8. D. Larbalestier, A.W. West, Action Met, University of Wisconsin Group, Summary Talk for the Workshops, Action Met, 32, p.1871, (1984).

9. P.J. Lee, D. Larbalestier, University of Wisconsin Group, Summary Talk for the Workshops, Multigraphical, Action Met, 35 , p.2523, (1987).

10. M. Garber, A.K. Ghosh, and W.B. Sampson, "The Effect of Self Field on the Critical Current Determination of Multifilamentary Superconductors,"IEEE Trans. Mag, Vol. MAG25, pp. 1940-1944, March 1989.

11. M. Garber and W.B. Sampson,"Test Methods for Cable Critical Currents and Normal State Resistance", SSC Technical Note No. 70,SSC-N-488, (1988).

12. M. Garber and W.B. Sampson, "Quality Control Testing of Cables for Accelerator Magnets," Super Collider 1, M. McAshan, Ed., Plenum Publishing Corp., NY, NY. 1989.

13. J.M. Royet and R.M. Scanlan,"Development of Scaling Rules for Rutherford Type Superconducting Cables", these proceedings.

14. R.M. Scanlan, J. Royet, R. Hannaford, "Fabrication of Rutherford Type Superconducting Cables for Construction of Dipole Magnets", presented at the 1988 ICMC Conference on Cryogenic Materials Applications and Properies, Shenyang, PRC (to be published). 